\title{
The Danish Cardiac Rehabilitation Database
}

This article was published in the following Dove Press journal:

Clinical Epidemiology

25 October 2016

Number of times this article has been viewed

Ann-Dorthe Zwisler,' Henriette Knold Rossau,' Anne Nakano, 2,3 Sussie Foghmar, ${ }^{4}$ Regina Eichhorst, ${ }^{5}$

Eva Prescott, ${ }^{6}$ Charlotte Cerqueira, ${ }^{7}$ Anne Merete Boas Soja, ${ }^{4}$ Gunnar $\mathrm{H}$ Gislason, ${ }^{8-10}$ Mogens Lytken Larsen, ${ }^{5}$ Ulla Overgaard Andersen, " Ida Gustafsson, ${ }^{4}$ Kristian K Thomsen, ${ }^{12}$ Lene Boye Hansen, ${ }^{13}$ Signe Hammer, ${ }^{14}$ Lone Viggers, ${ }^{15}$ Bo Christensen, ${ }^{16}$ Birgitte Kvist, ${ }^{17}$ Cecilie Lindström Egholm, ${ }^{18}$ Ole May ${ }^{19}$

On behalf of the Working Group of Preventive Cardiology and Rehabilitation, Danish Society of Cardiology, and the Working Group of Cardiac Clinical Registries, Danish Society of Cardiology

'Danish Centre for Rehabilitation and Palliative Care, Odense University Hospital and University of Southern Denmark, Odense, ${ }^{2}$ Department of Clinical Epidemiology, Aarhus University Hospital, ${ }^{3}$ Registry Support Centre (West) - Clinical Quality Improvement \& Health Informatics, Aarhus, ${ }^{4}$ Department of Cardiology, Copenhagen University Hospital, Hvidovre, ${ }^{5}$ Department of Cardiology, Aalborg University Hospital, Aalborg, ${ }^{6}$ Department of Cardiology Bispebjerg Hospital, University of Cardiolog, Bispebjerg Hospital, University of Centre (East) - Epidemiology and Biostatistics, Centre (East) - Epidemiology and Biostatistics,
Research Centre for Prevention and Health, the Capital Region of Denmark, Glostrup, ${ }^{8}$ Department of Cardiology, Copenhagen University Hospital Gentofte, Hellerup, ${ }^{9}$ The Danish Heart Foundation, Copenhagen, ${ }^{10} \mathrm{The}$ National Institute of Public Health, University of Southern Denmark, "Department of Cardiology, Holbaek Hospital, University of Copenhagen, Copenhagen, ${ }^{12}$ Department of Cardiology, Hospital of Southwest Jutland, Esbjerg, ${ }^{13}$ Department of Cardiology, Gentofte Hospital, Gentofte, ${ }^{14}$ Department of Occupational Therapy and Physiotherapy, Herlev Hospital, Herlev, ${ }^{15}$ Department of Nutrition, Regional Hospital West Jutland Holstebro, ${ }^{16}$ Department of General Medicine School of Public Health, Aarhus University, Aarhus, ${ }^{17}$ Department of Health Care and Prevention, Municipality of Frederikshavn, Frederikshavn, ${ }^{18}$ The Regional Research Unit, Region Zealand, Roskilde, ${ }^{19}$ Department of Medicine, Cardiovascular Research Unit, Regional Hospital Herning, Herning, Denmark

Correspondence: Ann-Dorthe Zwisler Danish Centre for Rehabilitation and Palliative Care, Odense University Hospital and University of Southern Denmark, Vestergade 17, 5800 Odense, Denmark

Tel +45 2367 I28

Email ann.dorthe.olsen.zwisler@rsyd.dk
Aim of database: The Danish Cardiac Rehabilitation Database (DHRD) aims to improve the quality of cardiac rehabilitation (CR) to the benefit of patients with coronary heart disease (CHD). Study population: Hospitalized patients with CHD with stenosis on coronary angiography treated with percutaneous coronary intervention, coronary artery bypass grafting, or medication alone. Reporting is mandatory for all hospitals in Denmark delivering CR. The database was initially implemented in 2013 and was fully running from August 14, 2015, thus comprising data at a patient level from the latter date onward.

Main variables: Patient-level data are registered by clinicians at the time of entry to CR directly into an online system with simultaneous linkage to other central patient registers. Follow-up data are entered after 6 months. The main variables collected are related to key outcome and performance indicators of CR: referral and adherence, lifestyle, patient-related outcome measures, risk factor control, and medication. Program-level online data are collected every third year.

Descriptive data: Based on administrative data, approximately 14,000 patients with CHD are hospitalized at 35 hospitals annually, with $75 \%$ receiving one or more outpatient rehabilitation services by 2015 . The database has not yet been running for a full year, which explains the use of approximations.

Conclusion: The DHRD is an online, national quality improvement database on CR, aimed at patients with CHD. Mandatory registration of data at both patient level as well as program level is done on the database. DHRD aims to systematically monitor the quality of CR over time, in order to improve the quality of CR throughout Denmark to benefit patients.

Keywords: secondary prevention, coronary heart disease, cardiovascular prevention, clinical quality registry, clinical database, quality improvement

\section{Aim of database}

Cardiovascular prevention and rehabilitation improves functional and clinical status, health-related quality of life, and prognosis in patients with coronary heart disease (CHD) recovering from acute events and invasive interventions. ${ }^{1}$ For more than a decade, cardiac rehabilitation (CR) has been recommended for CHD as part of integrated cardiac care. ${ }^{2,3}$ Despite this, studies from the US and Europe, including Denmark, have documented that less than half of eligible patients participate in CR. ${ }^{4}$ Systematic monitoring of delivery and outcomes of CR is recommended to meet this challenge. . $^{5}$ Thus, the national working group on preventive cardiology and rehabilitation, under the Danish Society of Cardiology, initiated a national clinical quality registry on CR approved by the Danish Health and Medicines Authority, in 2011. Although Danish Cardiac Rehabilitation Database (DHRD) was initially implemented on September 1, submit your manuscript | www.dovepress.com

Dovepress

http://dx.doi.org// 0.2/47/CLEP.S99502
Clinical Epidemiology 2016:8 45 I-456 (Thematic series on clinical quality databases in Denmark) 45 I (c) (i) (5) ๑) 2016 Zwisler et al. This work is published and licensed by Dove Medical Press Limited. The full terms of this license are available at https://www.dovepress.com/tterms. Bou hereby accept the Terms. Non-comporate the Creative Commons Attribution - Non Commercial (unported, v3.0) License (hittp://creativecommons.org/licenses/by-nc/3.0/). By accessing the work permission for commercial use of this work, please see paragraphs 4.2 and 5 of our Terms (https://www.dovepress.com/terms.php). 
2013, as a result of a breakdown of the database system, data collection ceased until August 14, 2015, at which point the database was implemented once again.

The overall aim of the DHRD is to monitor and improve the quality of Phase II CR throughout Denmark, in order to improve the outcome for patients recovering from cardiac events. Phase II CR in Denmark refers to the initial 8-12 weeks of outpatient $C R$ performed at hospitals and municipalities. Data are collected at a patient level as well as program level (Figure 1), as recommended by scientific associations in Europe and the US. ${ }^{5,6}$ Furthermore, the database aims to support research within the field of CR.

\section{Study population}

It is mandatory for all hospitals delivering Phase II CR to register all patients onto the DHRD, who are discharged alive and receiving CR following hospitalization for $\mathrm{CHD}$ (ie, acute coronary syndrome, or stable angina pectoris with proven stenosis on coronary angiography treated with percutaneous coronary intervention, coronary artery bypass grafting, or medication alone). All patients discharged alive from hospitals are identified from the National Patient Register ${ }^{7}$ using the WHO's International Classification of Diseases, 10th edition (ICD-10) coding system: acute coronary syndrome (ST-elevation myocardial infarction, non-ST-elevation myocardial infarction, and unstable angina) as primary diagnosis, or secondary diagnoses (DI210-DI219, DI248, DI240, DI249) and stable angina pectoris as primary diagnoses (DI209, DI251, DI251B, DI251C).
Furthermore, the Nordic Classification of Surgical Procedures is used to identify coronary angiograms and invasive procedures (coronary angiograms: UXAC40, UXAC85, UXAC90, UXUC85, UXUC86, UXUC87, UFYA20; percutaneous coronary intervention: KFNG00, KFNG02, KFNG02A, KFNG05, KFNG05A, KFNG10, KFNG12, KFNG20, KFNG22, KFNG30, KFNG40, KFNG96, KZFX01; and coronary artery bypass grafting: KFNA, KFNB, KFNC, KFND, KFNE, KFNF, KFNH, KFNJ, KFNK, KFNW).

The database will include information on approximately 14,000 patients annually. Based on administrative data on ambulatory visits (ie, data from the Danish National Patient Register $^{7}$ cross-checked with procedure codes referring to CR services), $75 \%$ of eligible patients are receiving one or more outpatient rehabilitation services from all 35 hospitals in the five regions of Denmark that were delivering $\mathrm{CR}$ in Denmark by $2013 .{ }^{8}$ The database is also capable of including other patient groups receiving CR.

\section{Data collection}

Patient-level data are collected by the clinical team and registered directly onto an online system at the time of entry into Phase II CR. The team comprises multidisciplinary professionals involved in the rehabilitation intervention (ie, nurses, medical doctors, physiotherapists, and dieticians). To minimize the registration workload and double registration, simultaneous linkage to national administrative patient registers has been established (the Danish Civil Registration

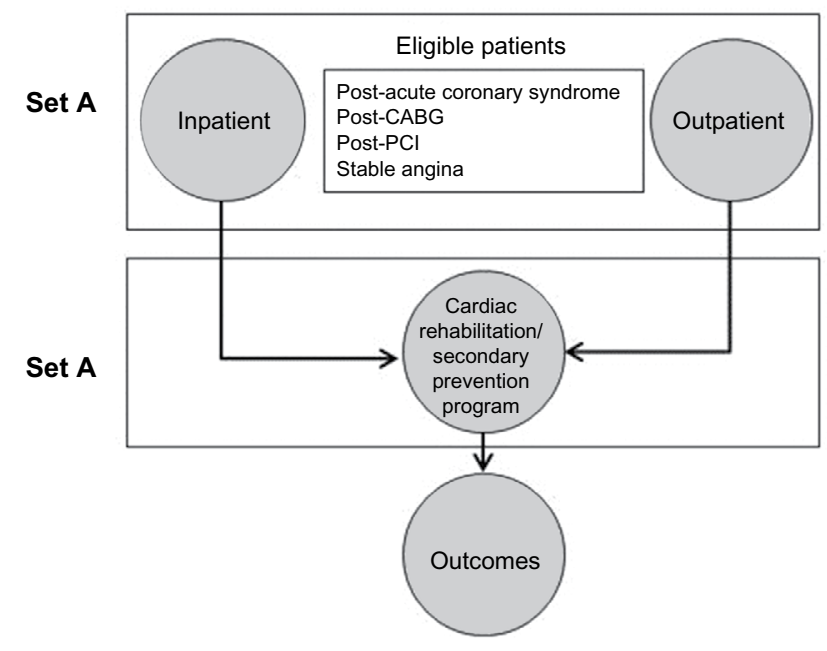

Patient Level $\quad$ Program

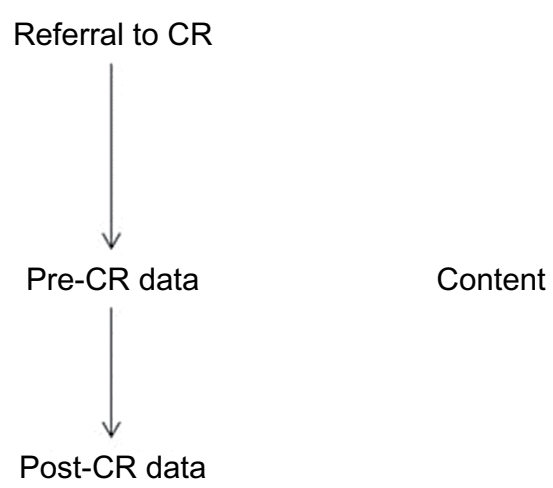

Figure I Datasets and level of data collection.

Note: Reprinted from J Cardiopulm Rehabil Prev, 27(5), Thomas RJ, King M, Lui K, et al, AACVPR/ACC/AHA 2007 performance measures on cardiac rehabilitation for referral to and delivery of cardiac rehabilitation/secondary prevention services, 260-290, ${ }^{6}$ Copyright @2007, with permission from Elsevier.

Abbreviations: CABG, coronary artery bypass grafting; $\mathrm{CR}$, cardiac rehabilitation; $\mathrm{PCI}$, percutaneous coronary intervention. 
System, ${ }^{9}$ the Danish National Patient Register, ${ }^{7}$ and the Danish National Database of Reimbursed Prescriptions). ${ }^{10}$ Linkage to the Clinical Laboratory Information System ${ }^{11}$ is also planned. At baseline, data are captured from the aforementioned registers and then validated and approved by the clinical staff, by reading and validating the captured information. Follow-up data is later entered manually at 6 months follow-up. Registration of data into the DHRD began on August 14, 2015, which led to the collection of data on 3,846 patients by March 2016. The quality of data is assessed as part of an annual data audit with feedback to clinicians.

\section{Main variables}

The variables recorded in the DHRD are related to patient characteristics at baseline, for example, smoking status, exercise capacity, height, weight, blood pressure, and pharmacological therapy. Also, data on performed diagnostic tests (eg, diabetes and depression) are recorded in the database, along with the individual plan for rehabilitation (eg, training sessions, dietary treatment, and/or smoking cessation). Data on physical capacity, lifestyle, and patient-reported outcome measures are reentered at follow-up, in order to monitor progression and outcome of CR. Table 1 lists the key data collected.

The data collected are aligned with the European Core CR dataset (McGee, unpublished data, 2004) and the variables of European Cardiac Rehabilitation Database project, in order to make sure that data from Denmark can be compared to data from other European countries. Data at a program level are collected every third year through

Table I Main variables collected as part of the Danish Cardiac Rehabilitation Database (patient-level and program-level data) by 2015

\begin{tabular}{|c|c|c|}
\hline Variable & \multicolumn{2}{|l|}{ Description } \\
\hline \multicolumn{3}{|l|}{ Patient-level data } \\
\hline \multicolumn{3}{|l|}{ Descriptive data } \\
\hline Sociodemographics & Sex, age, education, marital status, cohabitation status, driving license & \\
\hline Clinical descriptors & CHD characteristic, LVEF, cardiac rhythm, anthropomorphic measures & \\
\hline Severity of disease & NYHA, CCS & \\
\hline Comorbidity & COPD, DM, nephropathy, alcohol intake, other & \\
\hline Psychosocial aspects & Screening for depression, labor market attachment, sick leave & \\
\hline Outcome measures & Proportion of patients & Standard \\
\hline Referral to CR & With IHD assessed for eligibility & $>90 \%$ \\
\hline \multirow[t]{2}{*}{ Participation in CR } & Participating in CR among all patients with diagnosed IHD, admitted to a department of cardiology & $>35 \%$ \\
\hline & With IHD continuing rehabilitation among CR participants & $>75 \%$ \\
\hline \multirow[t]{2}{*}{ Exercise capacity } & With IHD completing at least $80 \%$ of planned training sessions & $>70 \%$ \\
\hline & $\begin{array}{l}\text { With IHD offered training sessions at the hospital, gaining at least } 10 \% \text { in exercise capacity in a bicycle } \\
\text { test or 6-minute walking test }\end{array}$ & $>80 \%$ \\
\hline Smoking & With IHD nonsmoking at completion of CR among patients smoking at admission prior to rehabilitation & $>60 \%$ \\
\hline Dietary treatment & $\begin{array}{l}\text { With IHD receiving dietary treatment by a clinical dietitian/Master of Science in Clinical Nutrition, at } \\
\text { completion of } C R\end{array}$ & Undecided \\
\hline LDL-cholesterol & With IHD which at the end of CR program has LDL-cholesterol $<1.8 \mathrm{mmol} / \mathrm{L}$ or a $50 \%$ decrease & $>60 \%$ \\
\hline Blood pressure & With IHD which at the end of CR program has a consultation blood pressure below $140 / 90 \mathrm{mmHg}$ & $>70 \%$ \\
\hline Screening for DM & With IHD and without diagnosed diabetes by admission, screened for diabetes at the end of CR & $>90 \%$ \\
\hline Screening for depression & With acute coronary syndrome who has been screened for depression by completion of CR & $>80 \%$ \\
\hline Antithrombotic therapy & With IHD receiving antiplatelet treatment by completion of $\mathrm{CR}$ & $>95 \%$ \\
\hline Statin therapy & With IHD receiving statin therapy by completion of $C R$ & $>80 \%$ \\
\hline $\begin{array}{l}\text { Beta-blocker therapy } \\
\text { (without heart failure) }\end{array}$ & With acute coronary syndrome receiving beta-blocker treatment by completion of CR & $>80 \%$ \\
\hline Variable & Description & \\
\hline \multicolumn{3}{|l|}{ Program-level data } \\
\hline Referral procedures & \multicolumn{2}{|l|}{$\begin{array}{l}\text { How are patients referred to CR, how long after discharge is the patient enrolled in CR program, how long after } \\
\text { discharge are the physical training sessions started, onward referral }\end{array}$} \\
\hline Program content & \multicolumn{2}{|l|}{$\begin{array}{l}\text { Which elements of CR are offered, for example, physical training, assessment of physical fitness, patient education, } \\
\text { psychosocial support, dietary treatment, screening for diabetes, smoking cessation }\end{array}$} \\
\hline Organization & \multicolumn{2}{|l|}{ Staff, number of patients, number of beds } \\
\hline Safety and documentation & \multicolumn{2}{|l|}{ Procedures related to safety during $C R$ and documentation of effect } \\
\hline
\end{tabular}

Note: A full list of variables is available in Danish at the Web site of the database (http://www.kcks-vest.dk/kliniske-kvalitetsdatabaser/hjerterehabilitering/).

Abbreviations: CCS, Canadian Cardiovascular Society; CHD, coronary heart disease; COPD, chronic obstructive pulmonary disease; CR, cardiac rehabilitation; DM, diabetes mellitus; IHD, ischemic heart disease; LDL, low-density lipoprotein; LVEF, left ventricular ejection fraction; NYHA, New York Heart Association. 
surveys targeted at CR staff. These surveys gather information about the structure and provision of $\mathrm{CR}$, and provide program-level information that can be compared with patient outcome over time.

\section{Follow-up}

A set of outcome variables has been defined and approved nationally, in order to provide a set of benchmark quality indicators. Table 1 provides a list of quality indicators and benchmark standards. The performance on the quality indicators is published in annual feedback reports at a national, regional, and hospital level as part of the annual audit of $\mathrm{CR}$. The indicator list and benchmarks are subject to regular adjustments, in order to keep the database in line with current evidence.

\section{Examples of research}

The database has been implemented since the summer of 2015; consequently, the first patient-level data will be available by autumn 2016. Applications for access to use data are reviewed by the Chair and Executive Committee upon application to the Danish Clinical Registries. In the short term, program-level data and administrative data have been presented as part of an annual report from $\mathrm{DHRD}^{8}$ and will be analyzed as part of an implementation research program investigating the gap between guidelines, clinical practice, and use of a clinical registry. ${ }^{12}$

\section{Ethics, funding, and administrative issues}

Data are collected and maintained according to Danish Data Protection Laws and Regulations, without the need to obtain patient consent. The database is fully funded by the Danish government.

The DHRD was initiated by the national working group on preventive cardiology and rehabilitation, under the Danish Society of Cardiology, and was approved as a national clinical quality registry on CR by the Danish Health and Medicines Authority in 2011. The DHRD is supported by the cross-disciplinary professional associations: the Danish Society of Cardiology, the Danish Nurses' Organisation, the Association of Danish Physiotherapists, and the Danish Association of Clinical Dieticians. The database is available at www.danheart.dk; however, this Web site can only be accessed through the Danish hospital Internet networks.

The Danish Clinical Registries, which constitutes the infrastructure of the Danish national clinical quality registries, has responsibility for the maintenance of majority of the data and data protection, as well as seeking funding. The database is headed by a Steering Committee with an elected Chair, an Executive Committee, and an Academic Secretariat.

\section{Discussion}

The national DHRD, aimed at monitoring and improving the quality of CR programs, has recently been established in Denmark. The DHRD is unique due to the direct and simultaneous linkages to the administrative hospital registers. This resource makes follow-up on clinically important outcomes, such as the number of hospitalizations and mortality rate, directly accessible.

Improving patient care is the overall aim of the database. Accreditation by use of clinical quality registries has been pointed out as an important tool to improve clinical practice within CR and clinical follow-up care ${ }^{13}$ (Figure 2), and referral to $\mathrm{CR}$ has been added as a performance measure following acute coronary syndrome by the European Society of Cardiology and the American Heart Association. ${ }^{14,15}$ The growing literature indicates that clinical quality registries can provide vital information that can be used to facilitate improvements in practice ${ }^{16}$ with positive effects primarily on the processes of care, whereas measures on outcome of care are less often positively affected. ${ }^{16}$ Findings, however, are heterogeneous, indicating that neither a registry itself nor the reporting of data initiates change as quality improvement requires comprehensive approaches, ${ }^{17}$ including successful implementation of the registry and continuous data quality assurance, as well as transparency and timely feedback. ${ }^{18}$ Based on experiences from the field of stroke care, embracing a comprehensive quality assurance approach, including a culture with focus on quality, thorough data entry, and availability of feedback as well as willingness to act on feedback, is critical in order to achieve improved quality of care. ${ }^{18}$ This cannot be achieved by DHRD alone, but is a shared responsibility of the CR team and the health care sector.

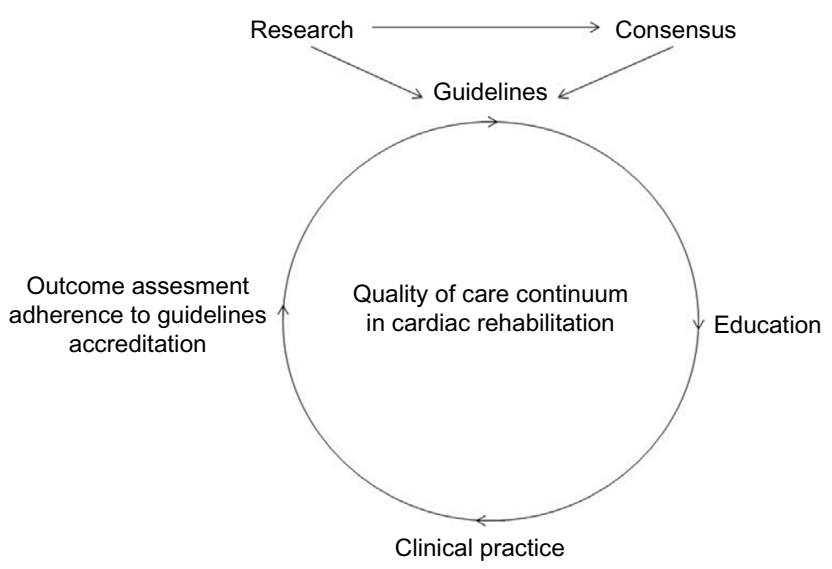

Figure 2 Quality of care continuum in cardiac rehabilitation and secondary prevention.

Note: Zwisler AD, Bjarnason-Wehrens B, McGee H, et al. Eur J Prev Cardiol: 19(2). Pp. 143-150, ${ }^{13}$ copyright $\bigcirc 2012$ by SAGE Publications. Reprinted by permission of SAGE Publications, Ltd. 
The DHRD includes all hospitals offering CR and will, therefore, reflect all hospital-based CR services at a national level. Since 2007, the municipalities in Denmark have had the overall responsibility for prevention and rehabilitation following discharge. CR services were, hence, transferred from hospitals to the municipalities (either partly or fully) in 2007. Quality assurance and accreditation of municipalitybased CR will, therefore, become an important focus for DHRD in the future.

A high reporting and coverage rate of patients with CHD is, therefore, essential. Coverage of the database will be closely monitored and routinely evaluated by matching data to the administrative data in the Danish National Patient Register. ${ }^{7}$ The aim is to achieve $>90 \%$ coverage of CR activities in all CR programs.

\section{Conclusion}

DHRD is an online, clinical quality database that aims toward providing higher quality $\mathrm{CR}$ for patients with $\mathrm{CHD}$ in Denmark. DHRD systematically monitors the quality of CR provision across programs over time. Data can be assessed as a part of research related to both the outcome and organization of $\mathrm{CR}$.

\section{Acknowledgments}

This article was written on behalf of the Steering Committee of the Danish Cardiac Rehabilitation Database. We sincerely thank all the departments and multidisciplinary clinical staff, who are providing CR to patients with CHD and are responsible for collecting data to ensure the quality of $\mathrm{CR}$. Also, we thank Søren Paaske Johnsen, who contributed to the development of the database.

This paper was funded by the Program for Clinical Research Infrastructure, established by the Lundbeck Foundation and the Novo Nordisk Foundation and administered by the Danish Regions.

\section{Disclosure}

The authors report no conflicts of interest in this work.

\section{References}

1. Anderson L, Taylor RS. Cardiac rehabilitation for people with heart disease: an overview of Cochrane systematic reviews. Cochrane Database Syst Rev. 2014;12:Cd011273.

2. Perk J, De Backer G, Gohlke H, et al. European Guidelines on cardiovascular disease prevention in clinical practice (version 2012) The Fifth Joint Task Force of the European Society of Cardiology and other societies on cardiovascular disease prevention in clinical practice (constituted by representatives of nine societies and by invited experts) Developed with the special contribution of the European Association for Cardiovascular Prevention \& Rehabilitation (EACPR). Eur Heart J. 2012:33(13):1635-1701.
3. Smith SC Jr, Benjamin EJ, Bonow RO, et al. AHA/ACCF secondary prevention and risk reduction therapy for patients with coronary and other atherosclerotic vascular disease: 2011 update: a guideline from the American Heart Association and American College of Cardiology Foundation. Circulation. 2011;124(22):2458-2473.

4. Piepoli MF, Corra U, Benzer W, et al. Secondary prevention through cardiac rehabilitation: from knowledge to implementation. A position paper from the Cardiac Rehabilitation Section of the European Association of Cardiovascular Prevention and Rehabilitation. Eur J Cardiovasc Prev Rehabil. 2010;17(1):1-17.

5. Piepoli MF, Corra U, Adamopoulos S, et al. Secondary prevention in the clinical management of patients with cardiovascular diseases. Core components, standards and outcome measures for referral and delivery: a policy statement from the cardiac rehabilitation section of the European Association for Cardiovascular Prevention \& Rehabilitation. Endorsed by the Committee for Practice Guidelines of the European Society of Cardiology. Eur J Prev Cardiol. 2014;21(6): 664-681.

6. Thomas RJ, King M, Lui K, et al. AACVPR/ACC/AHA 2007 performance measures on cardiac rehabilitation for referral to and delivery of cardiac rehabilitation/secondary prevention services. $J$ Cardiopulm Rehabil Prev. 2007;27(5):260-290.

7. Lynge E, Sandegaard JL, Rebolj M. The Danish National Patient Register. Scand J Public Health. 2011;39(7 Suppl):30-33.

8. Dansk Hjerterehabiliteringsdatabase. Strukturelle forhold og opgørelse af patientgrundlag og aktivitet $i$ Landspatientregistret 2013. Aarhus: Regionernes Kliniske Kvalitetsudviklings Program; 2015.

9. Pedersen CB. The Danish Civil Registration System. Scand J Public Health. 2011;39(7 Suppl):22-25.

10. Johannesdottir SA, Horvath-Puho E, Ehrenstein V, Schmidt M, Pedersen L, Sorensen HT. Existing data sources for clinical epidemiology: The Danish National Database of Reimbursed Prescriptions. Clin Epidemiol. 2012;4:303-313.

11. Grann AF, Erichsen R, Nielsen AG, Froslev T, Thomsen RW. Existing data sources for clinical epidemiology: The clinical laboratory information system (LABKA) research database at Aarhus University, Denmark. Clin Epidemiol. 2011;3:133-138.

12. Nieuwlaat R, Schwalm JD, Khatib R, Yusuf S. Why are we failing to implement effective therapies in cardiovascular disease? Eur Heart J. 2013;34(17):1262-1269.

13. Zwisler AD, Bjarnason-Wehrens B, McGee H, et al. Can level of education, accreditation and use of databases in cardiac rehabilitation be improved? Results from the European Cardiac Rehabilitation Inventory Survey. Eur J Prev Cardiol. 2012;19(2):143-150.

14. Wright RS, Anderson JL, Adams CD, et al. 2011 ACCF/AHA focused update incorporated into the ACC/AHA 2007 guidelines for the management of patients with unstable angina/non-ST-elevation myocardial infarction: a report of the American College of Cardiology Foundation/American Heart Association Task Force on practice guidelines developed in collaboration with the American Academy of Family Physicians, Society for Cardiovascular Angiography and Interventions, and the Society of Thoracic Surgeons. JAm Coll Cardiol. 2011;57(19): e215-367.

15. Antman EM, Hand M, Armstrong PW, et al. 2007 focused update of the ACC/AHA 2004 guidelines for the management of patients with ST-elevation myocardial infarction: a report of the American College of Cardiology/American Heart Association Task Force on Practice Guidelines. J Am Coll Cardiol. 2008;51(2):210-247.

16. van der Veer SN, de Keizer NF, Ravelli AC, Tenkink S, Jager KJ. Improving quality of care. A systematic review on how medical registries provide information feedback to health care providers. Int $J$ Med Inform. 2010;79(5):305-323.

17. Grol R, Grimshaw J. From best evidence to best practice: effective implementation of change in patients' care. Lancet. 2003;362(9391):1225-1230

18. Eldh AC, Fredriksson M, Halford C, et al. Facilitators and barriers to applying a national quality registry for quality improvement in stroke care. BMC Health Serv Res. 2014;14:354. 


\section{Publish your work in this journal}

Clinical Epidemiology is an international, peer-reviewed, open access, online journal focusing on disease and drug epidemiology, identification of risk factors and screening procedures to develop optimal preventative initiatives and programs. Specific topics include: diagnosis, prognosis, treatment, screening, prevention, risk factor modification,

Submit your manuscript here: https://www.dovepress.com/clinical-epidemiology-journa systematic reviews, risk and safety of medical interventions, epidemiology and biostatistical methods, and evaluation of guidelines, translational medicine, health policies and economic evaluations. The manuscript management system is completely online and includes a very quick and fair peer-review system, which is all easy to use. 